\title{
Implementation of Risk Management with SCRUM to Achieve CMMI Requirements
}

\author{
Eman Talal Alharbi, M. Rizwan Jameel Qureshi \\ Faculty of Computing and Information Technology, King Abdulaziz University, Jeddah, Saudi Arabia \\ alharbi_eman@yahoo.com, anriz@hotmail.com
}

\begin{abstract}
Majority of the software development companies are practicing agile methods to develop high quality products. SCRUM is one of the most widely used agile methods. Capability maturity model integration (CMMI) is one of the quality standards for software companies. In this research, we propose an implementation of risk management with SCRUM in order to make it compatible with CMMI. We conducted a survey to validate the proposed solution. Questionnaire includes 20 questions that are divided into three goals. The proposed solution is validated through survey with support of $70.94 \%$. We anticipate that the proposed solution will enable software companies to achieve CMMI and it will also improve the quality of software products.
\end{abstract}

Index Terms-SCRUM, Capability Maturity Model Integration (CMMI), risk management, risk register, sprint, burn-down-chart.

\section{INTRODUCTION}

Majority of the organizations are improving software development processes in order to achieve high quality products. The Capability Maturity Model Integration (CMMI) is one of the ways to improve software development processes. CMMI provides an integrated approach across the enterprise for improving processes. Scrum is one of the best methods that can be used with CMMI to improve the software development processes. Scrum is an iterative and incremental agile software development framework for managing software projects/products. Scrum is compatible with CMMI level 2 with a high percent but it is compatible with level 3 only with $24 \%$. This research focuses on how we can adapt Scrum more compatible with CMMI to achieve level 3 by the implementation of risk management.

Risk management is one of the most important practices in software industry. Risk management is not indicated in the practices of Scrum where as it is one of important practices of CMMI level 3. In this paper, we discuss how risk management can be a part of the Scrum sprints. We propose a risk register that can be used as a tool for risk management.

Further paper is organized as follows.

Section II covers the related work. Section III describes the problem and the proposed solution.
Validation of the proposed solution is illustrated in section IV.

\section{RELATED WORK}

Gannon [1] explores the fundamentals of SCRUM as well as how this agile development methodology has been implemented on a project at the Johns Hopkins University Applied Physics Laboratory. The team members faced some difficulty in time management, colocated with the rest of the team and each team member's amenability to change [1]. Guang [2] has developed a vehicle management system using scrum as software process method with the template visual studio 2010 in order to improve the productivity and efficiency of SCRUM.

Lukasiewicz and Miler [3] proposed a C-S model to improve an actual software development process that defined a diagnostic questionnaire, a practice selection algorithm, an application process and built a software tool, these proposals implemented on two case studies. $3.5 \%$ of the suggested practices were rejected by the companies. Some $24.5 \%$ of suggestions were evaluated as not applicable for organizational or economic reasons, which leaves room for further improvement of proposed questionnaire. It is discussed that how to implement collaborative agile scrum software for complex multivendor competing environments [4]. A framework is proposed for collaborative agile software development. The roles of project manager, product owner and scrum master are specified. The specialty of this framework is that scrum master can work with product owner and business analyst. The main limitations of this study are [4] poor collaboration between teams due to distance factor (different time zone) and lack of time commitment from the customer representatives.

An extension of the scrum framework is proposed to improve learning of teams [5]. This extension is expected to support organizational learning and deliver benefits at strategic level. Four different flexible agile methods are identified to transfer knowledge across projects:

- $\quad$ mentoring and coaching;

- $\quad$ staffing project teams with members of other projects;

- $\quad$ articipation in multi-project reviews;

- anticipation in multi-project retrospectives. 
These four methods can be used as a guide for development of strategies to promote learning across scrum projects [5]. Samina and Javed [6] introduce a framework that is a customized approach to improve software development by integrating CMMI and scrum.

Table 1. brief description of related work

\begin{tabular}{|c|c|}
\hline Title of Papers & Limitations \\
\hline An Agile Implementation of SCRUM [1] & $\begin{array}{l}\text { - In the beginning most of the team members on the project working with } \\
\text { scrum found difficulty in time management } \\
\text { - Another limitation was each team member's amenability to change } \\
\text { - Another limitation is for the team was that one team member was not co- } \\
\text { located with the rest of the team. }\end{array}$ \\
\hline study and practice of Import Scrum agile software development [2] & $\begin{array}{l}\text { This paper does not focus on the difficulty of the Scrum master to plan, } \\
\text { structure and organize a project that lacks a clear definition. }\end{array}$ \\
\hline $\begin{array}{l}\text { Improving agility and discipline of software development with the } \\
\text { Scrum and CMMI. [3] }\end{array}$ & $\begin{array}{l}\text { - } 3.5 \% \text { of the suggested practices were rejected by the companies. } \\
\text { - Some } 24.5 \% \text { of suggestions were evaluated as not applicable for } \\
\text { organizational or economic reasons, }\end{array}$ \\
\hline $\begin{array}{l}\text { Collaborative and Competitive } \\
\text { Development [4] }\end{array}$ & $\begin{array}{l}\text { - Distance factor due to the different time zone for collaboration } \\
\text { - lack of time commitment from the customer representatives } \\
\text { - larger customer with larger projects are unwilling to collaborate agile } \\
\text { software } \\
\text { - Problems in gathering and clarifying requirements are not mentioned. }\end{array}$ \\
\hline Scrum and CMMI - Going from Good to Great [7] & $\begin{array}{l}\text { - This paper not focuses carefully on cross functional team interactions and } \\
\text { dynamics. }\end{array}$ \\
\hline $\begin{array}{l}\text { Challenges Faced While Simultaneously Implementing CMMI and } \\
\text { Scrum [8] }\end{array}$ & $\begin{array}{l}\text { - This paper does not attempt to present an exhaustive list of the challenges } \\
\text { successfully faced and overcome by The Tax Company }\end{array}$ \\
\hline $\begin{array}{l}\text { Research on Combining Scrum with CMMI in Small and Medium } \\
\text { Organizations [9] }\end{array}$ & $\begin{array}{l}\text { - The organizations aiming to reach beyond the CMMI maturity level } 2 \text { are } \\
\text { not fully attended by using the Scrum practices. }\end{array}$ \\
\hline $\begin{array}{l}\text { Can scrum help to improve the project management process? A } \\
\text { study of the relationship between scrum and project management } \\
\text { process area of cmmi-dev } 1.3 \\
{[10]}\end{array}$ & $\begin{array}{l}\text { - Scrum practices do not leave a paper trail that can retrospectively } \\
\text { demonstrate the implementation of some of the SGs of CMMI } \\
\text { - SCRUM can't cover process area like: Risk Management, Supplier } \\
\text { Agreement Management and Quantitative Project Management } \\
\text { - Deferent meaning of product owner in CMMI \& SCRUM } \\
\end{array}$ \\
\hline $\begin{array}{l}\text { Mapping CMMI Project Management Process Areas to SCRUM } \\
\text { Practices [11] }\end{array}$ & $\begin{array}{l}\text { - Scrum does not cover all the specific practices of the project } \\
\text { management process area. } \\
\text { - Organizations searching higher maturity levels are not fully attended by } \\
\text { SCRUM practices. } \\
\text { - Other alternative practices are necessary to complement SCRUM and } \\
\text { address CMMI requirements. }\end{array}$ \\
\hline
\end{tabular}

Jeff et al. [7] assert that scrum and CMMI combination brings adaptability and predictability. It is suggested that Lean software model can be used as an operational tool for CMMI level 5 companies to identify improvement opportunities [8].

A case study is conducted by Miller and Haddad [9] to find the challenges in a growing software company to achieve CMMI level 2 while implementing Scrum. Five things are recommended for companies who are willing to achieve CMMI with scrum implementation [9].

- Invest money to train a team.

- Ensure active participation.

- Maintain optimum staffing level.

- Facilitate access to information.

- Establish effective communication.

Lina and Dan [10] mention that numerous problems are encountered while applying CMMI in small and medium software development organizations. These studies are written to identify the relationship between Scrum and CMMI [11-13]. It is found that the main relationship lies in the project management process areas.
It is also reported that scrum is not fully compliant with CMMI because a weak adherence of scrum to risk management area [11-13].

\section{The Problem StATEMENT AND The Proposed SOLUTUON}

The main problem is to find the appropriate alternative method that can be used with Scrum to achieve CMMI requirements without losing agility.

We have to adapt the most important practice 'risk management' that is required by most of the methodologies in order to achieve SCRUM compatibility with CMMI. This adaptation can be achieved by including a 'Risk Register' component. The main benefits of the 'risk register' component are management of risks and improve quality of process and project. The working of 'risk register' component is as follows.

\section{A. Risk Definition}

Risk factor is a direct result of uncertainty in a software project. The two main factors, to manage risks in a software project, are: 
- $\quad$ impact of risk (helpful/ harmful); - the source of the risk (internal/ external) [14].

Table 2. The main attributes of the proposed 'Risk Register' component

\begin{tabular}{|c|c|c|c|c|c|c|c|c|}
\hline Risk description & Data identified & probability & impact & Solution/ action & owner & status & exposure & priority \\
\hline $\begin{array}{l}\text { Serious security } \\
\text { flow discovered } \\
\text { may allow } \\
\text { hackers to } \\
\text { breach the } \\
\text { system security }\end{array}$ & $\begin{array}{l}\text { Gaps in the } \\
\text { security of the } \\
\text { application }\end{array}$ & $40 \%$ & 5 & $\begin{array}{l}\text { Hiring application } \\
\text { security expert, do } \\
\text { extra testing for } \\
\text { each module. }\end{array}$ & $\begin{array}{l}\text { scrum } \\
\text { owner/ } \\
\text { team }\end{array}$ & & 10 & 5 \\
\hline $\begin{array}{l}\text { Late in delivery } \\
\text { of the project }\end{array}$ & $\begin{array}{l}\text { Complexity in } \\
\text { specific code / } \\
\text { cause of } \\
\text { another risk }\end{array}$ & $25 \%$ & 4 & $\begin{array}{l}\text { Use CBD and other } \\
\text { extra resources }\end{array}$ & $\begin{array}{l}\text { scrum } \\
\text { team }\end{array}$ & & 4 & 4 \\
\hline $\begin{array}{l}\text { Fire, flood, bad } \\
\text { weather }\end{array}$ & Natural event & $5 \%$ & 2 & $\begin{array}{l}\text { Be sure to back up } \\
\text { the project at } \\
\text { different places, } \\
\text { keep working from } \\
\text { homes at the work } \\
\text { hours }\end{array}$ & $\begin{array}{l}\text { scrum } \\
\text { master }\end{array}$ & & 0.2 & 1 \\
\hline $\begin{array}{l}\text { Incorrect } \\
\text { modules of the } \\
\text { application }\end{array}$ & $\begin{array}{l}\text { Unclear / } \\
\text { Ambiguity in } \\
\text { requirements }\end{array}$ & $20 \%$ & 3 & $\begin{array}{l}\text { Focus on the } \\
\text { requirements and be } \\
\text { sure it's right } \\
\text { understood }\end{array}$ & $\begin{array}{l}\text { scrum } \\
\text { team }\end{array}$ & & 1.8 & 3 \\
\hline \multirow[t]{2}{*}{$\begin{array}{l}\text { Customer } \\
\text { suggest } \\
\text { additional } \\
\text { features }\end{array}$} & $\begin{array}{l}\text { New } \\
\text { requirements }\end{array}$ & $10 \%$ & 3 & $\begin{array}{l}\text { Add cost estimation } \\
\text { and new delivery } \\
\text { time }\end{array}$ & $\begin{array}{l}\text { scrum } \\
\text { owner }\end{array}$ & & 0.9 & 2 \\
\hline & & & & & & & Total $\approx 17$ & \\
\hline
\end{tabular}

\section{B. Risk Management}

Risk management plan is developed by software development team to precede, contain and mitigate the effects of risk to a project. Each risk will be analyzed in order to understand its source, effects, probability of loss and how a team can prevent it. The management plan includes attributes such as a brief risk description, the data which identify the risk, probability of occurrence of the risk, degree of its impact, the person who manages, controls, and takes action in response to a risk, action against risk and risk status [15].

\section{Risk Management Within Scrum}

It is necessary not to lose agility of a project while integrating risk management with scrum. We propose a 'Risk Register' component to track and manage risks in Scrum projects. The proposed 'Risk Register' component will contain risk assessments corresponding to a particular sprint to monitor how many risks will be added and removed. Fig. 1 shows the functioning of the proposed 'Risk Register' component.

The attributes used in the proposed 'Risk Register' component are:

1) risk description contains a brief description about the risk;

2) data identified causing a risk;

3) probability of a risk in percentage value (If the risk has a high percent of probability means high attention);

4) impact on the project (It ranges from 1 to 5);
5) way to solve a risk;

6) allocate resources to handle a risk;

7) status of a risk;

8) exposure;

9) priority high means manage first.

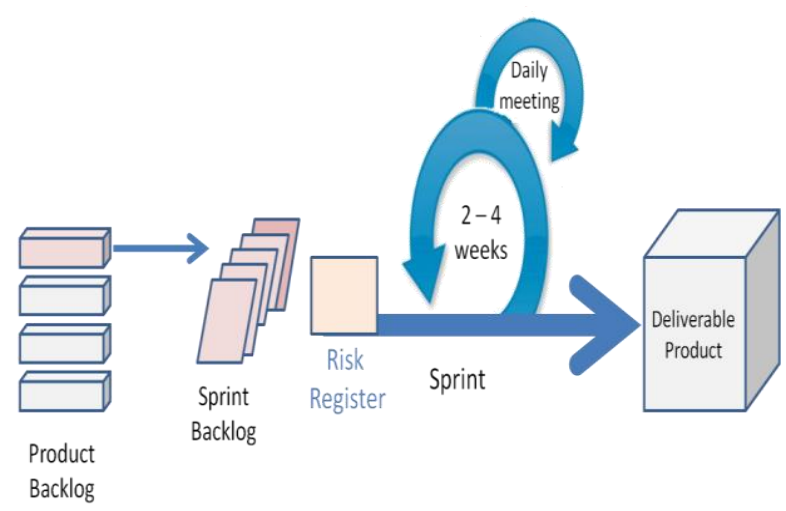

Fig 1. Functioning of the proposed 'Risk Register' component

The main attributes of the proposed 'Risk Register' component are shown in Table 2. The proposed 'Risk Register' will be used at each sprint to add suspected risks. Scrum team will use the 'Risk Register' component to deal with the risk before the implementation phase of a sprint. Team and 'Scrum Master' will review the risks using the proposed 'Risk Register' during sprint retrospective meeting. Table 3 shows to identify how many risks are removed during each sprint. Fig. 2 shows risk Burn-down chart that will used to represent the status of the risks. The ideal burn-down would be a linear 
decrease of consolidated risk exposure over the sprints [15].

Table 3. Diminishing Exposure through Sprints

\begin{tabular}{|l|l|}
\hline Sprint & Exposure \\
\hline 1 & 17 \\
\hline 2 & 15 \\
\hline 3 & 10 \\
\hline 4 & 7 \\
\hline 5 & 3 \\
\hline 6 & 0 \\
\hline
\end{tabular}

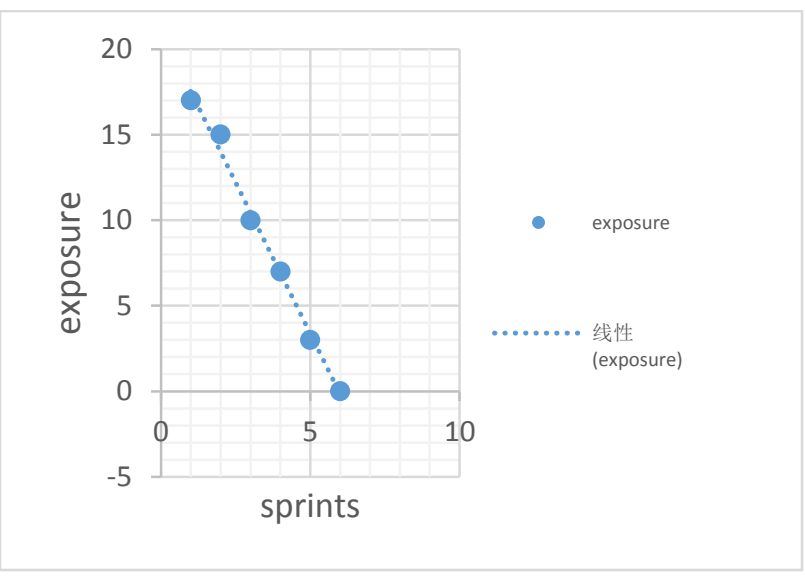

Fig 2. Burn down charts for Table 2

\section{VALIDATION}

Survey is used as a research design to validate the proposed solution. The survey contains 20 questions that are divided into three sections according to the three goals. Likert Scale is used ranging from 1 to 5 (strongly disagree, disagree, nominal, agree and strongly agree). The gathered data is statistically analyzed and results are displayed using frequency tables and bar charts.

\section{A. Cumulative Statisical Analysis of Goal 1 (Focusing on the Risk Management Practice)}

Risk management is the most practice that is required in CMMI level 3. This practice is not supported by Scrum. We integrated risk management into Scrum to achieve CMMI. The analysis of goal 1 is shown in Table 4.

We find that that $54.27 \%$ of the respondents are agreed and $14.89 \%$ are strongly agreed. While $0.81 \%$ of the respondents are strongly disagreed and $7.31 \%$ of the respondents are disagreed. $22.56 \%$ of the respondents are remained neutral. This result is displayed graphically in fig. 3 .

B. Cumulative Statisical Analysis of Goal 2 (Considering Risk Register as the Tool which Used to Manage the Risks)
Table 4. cumulative analysis of goal 1

\begin{tabular}{|c|c|c|c|c|c|}
\hline $\begin{array}{c}\text { Q. } \\
\text { No. }\end{array}$ & $\begin{array}{c}\text { Strongly } \\
\text { disagree }\end{array}$ & Disagree & Nominal & Agree & $\begin{array}{c}\text { Strongly } \\
\text { agree }\end{array}$ \\
\hline q1 & 2.44 & 2.44 & 24.39 & 65.85 & 4.88 \\
\hline q2 & 0 & 2.44 & 12.2 & 68.29 & 17.07 \\
\hline q3 & 0 & 2 & 19.51 & 65.85 & 12.2 \\
\hline q4 & 0 & 5 & 14.63 & 73.17 & 7.32 \\
\hline q5 & 2 & 19.51 & 17.07 & 31.71 & 29.27 \\
\hline q6 & 0 & 7.32 & 24.39 & 65.85 & 2 \\
\hline q7 & 0 & 9.76 & 12.2 & 31.71 & 46.34 \\
\hline q8 & 2 & 10 & 56.1 & 31.71 & 0 \\
\hline total & 6.44 & 58.47 & 180.49 & 434.14 & 119.08 \\
\hline avera & 0.81 & 7.31 & 22.56 & 54.27 & 14.89 \\
ge & & & & & \\
\hline
\end{tabular}

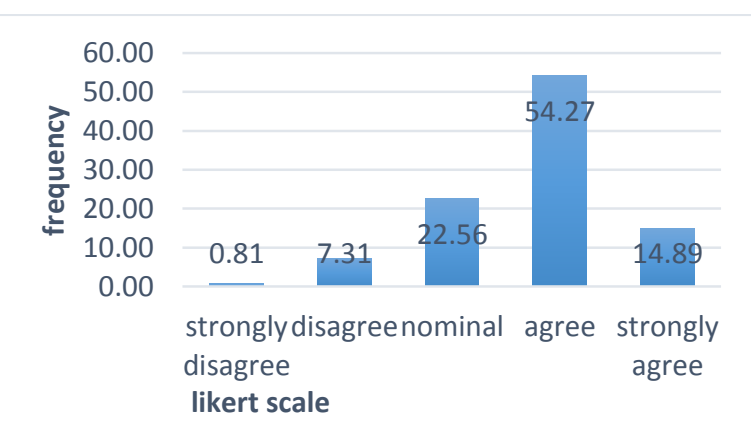

Fig 3. Cumulative analysis of goal 1

Table 5. cumulative analysis of goal 2

\begin{tabular}{|c|c|c|c|c|c|}
\hline Q. No. & $\begin{array}{c}\text { Strongly } \\
\text { disagreed }\end{array}$ & Disagreed & Nominal & Agreed & $\begin{array}{c}\text { Strongly } \\
\text { agreed }\end{array}$ \\
\hline $\mathrm{q} 1$ & 2.44 & 2.44 & 14.63 & 51.22 & 29.27 \\
\hline $\mathrm{q} 2$ & 0 & 7.32 & 21.95 & 41.46 & 29.27 \\
\hline $\mathrm{q} 3$ & 0 & 7.32 & 19.51 & 60.98 & 12.2 \\
\hline $\mathrm{q} 4$ & 0 & 4.88 & 9.76 & 30.02 & 46.34 \\
\hline $\mathrm{q} 5$ & 0 & 2.44 & 19.51 & 31.71 & 46.34 \\
\hline $\mathrm{q} 6$ & 2.44 & 7.32 & 36.59 & 26.83 & 26.63 \\
\hline $\mathrm{q} 7$ & 0 & 0 & 14.63 & 48.78 & 36.59 \\
\hline total & 4.88 & 31.72 & 136.58 & 291 & 226.64 \\
\hline average & 0.70 & 4.53 & 19.51 & 41.57 & 32.38 \\
\hline
\end{tabular}

We need to use a tool to implement the risk management with scrum. We proposed 'Risk Register' component. The result of this goal is placed in Table 5 .

Table 5 shows that $41.57 \%$ of the respondents are agreed and $32.38 \%$ of the respondents are strongly agreed with this usage. While only $4.53 \%$ of the respondents are disagreed and $0.7 \%$ of the respondents are strongly disagreed. $19.51 \%$ of the respondents are remained neutral. This result is displayed graphically in fig. 4 .

C. Cumulative Statisical Analysis of Goal 3 (Keeping the Agility of SCRUM) 
We proposed to use the 'Risk Register' component at each sprint in order to keep the agility in scrum. The result of goal is shown in Table 6.

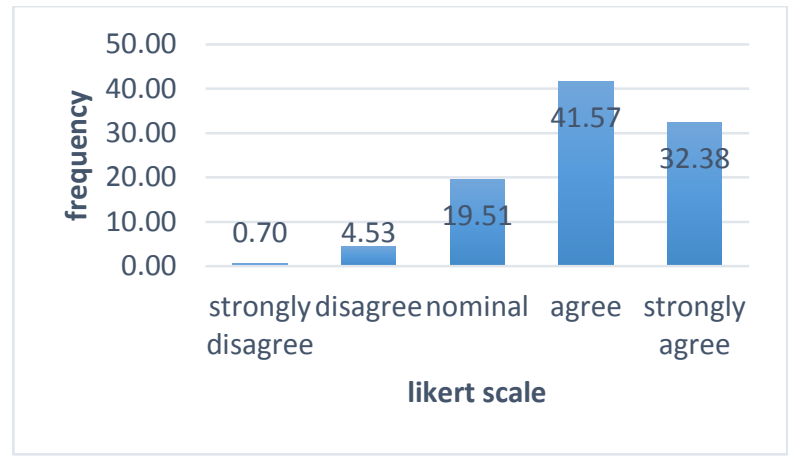

Fig 4. Cumulative analysis of goal 2

Table 6. cumulative analysis of goal 3

\begin{tabular}{|c|c|c|c|c|c|}
\hline Q. No. & $\begin{array}{c}\text { Strongly } \\
\text { disagree }\end{array}$ & Disagree & Nominal & Agree & $\begin{array}{c}\text { Strongly } \\
\text { agree }\end{array}$ \\
\hline $\mathrm{q} 1$ & 0 & 2.44 & 17.07 & 58.54 & 21.95 \\
\hline $\mathrm{q} 2$ & 0 & 7.32 & 19.51 & 48.78 & 24.39 \\
\hline $\mathrm{q} 3$ & 2.44 & 17.07 & 31.71 & 41.46 & 7.32 \\
\hline $\mathrm{q} 4$ & 2.44 & 19.51 & 21.95 & 48.78 & 7.32 \\
\hline $\mathrm{q} 5$ & 0 & 0 & 9.76 & 43.9 & 46.34 \\
\hline total & 4.88 & 46.34 & 100 & 241.46 & 107.32 \\
\hline average & 0.98 & 9.27 & 20.00 & 48.29 & 21.46 \\
\hline
\end{tabular}

Table 6 shows that $48.29 \%$ of the respondents are agreed and $21.46 \%$ strongly agreed while using the proposed 'Risk Register' component at each sprint to keep agility in Scrum. 9.27\% of the respondents are disagreed and $0.98 \%$ of the respondents are strongly disagreed. $21.46 \%$ of the respondents are nominal. The result of Table 6 is displayed graphically in fig. 5 .

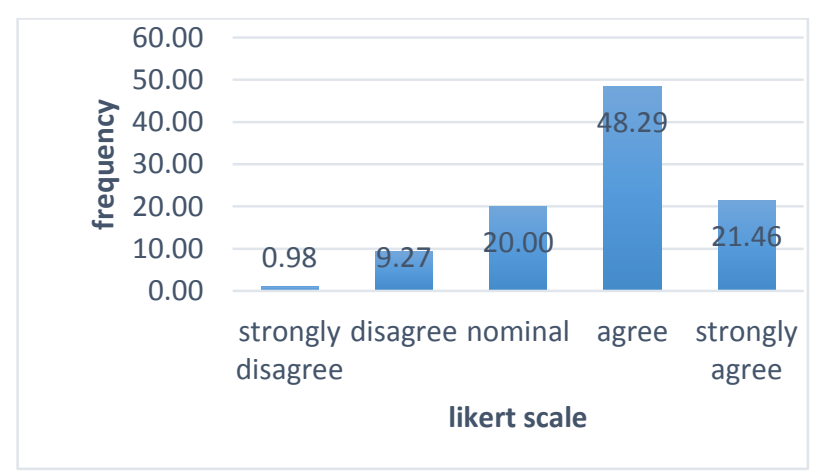

Fig 5. Cumulative analysis of goal 3

A final cumulative analysis of all the three goals is shown in Table $7.70 .94 \%$ of respondents are highly in favor the proposed solution, $7.94 \%$ of the respondents are disagreed and $20.69 \%$ are remained neutral. Fig. 6 shows graphical representation of the final cumulative analysis of three goals against the proposed solution.

Table 7. Final cumulative analysis of Three goals

\begin{tabular}{|c|c|c|c|}
\hline Goals & Disagree & Nominal & Agree \\
\hline Goal 1 & 8.1 & 22.56 & 69.14 \\
\hline Goal 2 & 5.22 & 19.51 & 73.94 \\
\hline Goal 3 & 10.23 & 20 & 69.75 \\
\hline Total & 23.55 & 62.07 & 212.83 \\
\hline Average & $7.85 \%$ & $20.69 \%$ & $70.94 \%$ \\
\hline
\end{tabular}

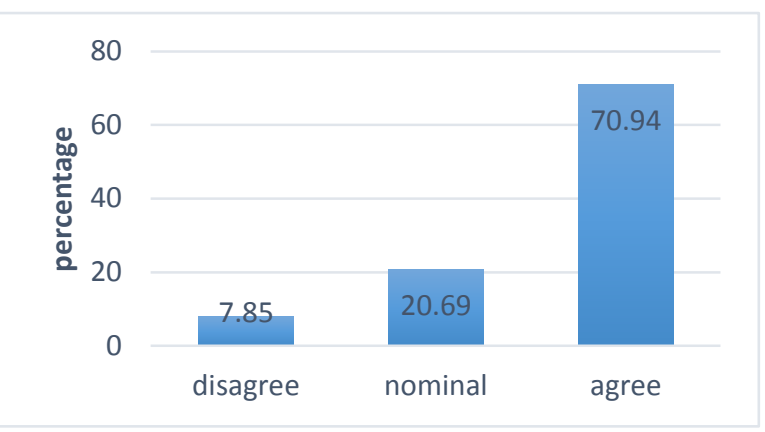

Fig 6. Final cumulative analysis of three goals

\section{CONCLUSION}

This paper is written in support of adapting Scum methodology to use with CMMI quality standard. This adaptation is achieved by proposing a 'Risk Register' component to cater the possible risks regarding failure of a software project. The main attributes of the proposed 'Risk Register' component are defined during this research. Scrum team will use the proposed component during all sprint review meetings. Survey is used as a research methodology to validate the proposed solution. The proposed solution is divided into three goals. A questionnaire is designed against three goals. Questionnaire is composed of twenty questions. The results are displayed using frequency tables and bar charts. A support of $70.94 \%$ is achieved against the proposed solution as shown in Table 7 and fig. 6. We anticipate that the proposed research will increase the chances of software companies who are willing to achieve CMMI while implementing Scrum as a software development methodology.

\section{REFERENCES}

[1] Gannon, M., An Agile Implementation of SCRUM, Aerospace Conference, p. 1-7, 2013.

[2] Guang-yong, H., Study and practice of Import Scrum agile software development, p. 217-220, 2011.

[3] Łukasiewicz, K., Miler, J., Improving agility and discipline of software development with the Scrum and CMMI, IET Software, 2012. 6(5): p. 416-422.

[4] Ramanujam, R., Lee, I., Collaborative and Competitive Strategies for Agile Scrum Development, 7th International Conference on Networked Computing and Advanced Information Management (NCM), p. 123-127, 2011. 
[5] Landaeta, E., Viscardi, S., Tolk, A., Strategic Management of Scrum Projects: An Organizational Learning Perspective, Int'l Technology Management Conference, p. 651-656, 2011.

[6] Samina Jan and Ali Javed, SCXTREME Framework: A Customized Approach of Process Improvements in Agile Blend with CMMI Practices in Pakistan, IJCNIS, 2013, 5(3): p. 69-78.

[7] Sutherland, J., Jakobsen, C.R., Johnson, K., Scrum and CMMI level 5: the magic potion for code warriors, Agile Conference, p. 13-17, 2007.

[8] Jakobsen, C. and Sutherland, J., Scrum and CMMI Going from Good to Great, Agile Conference, p. 333-337, 2009.

[9] James R. Miller and Hisham M. Haddad, Challenges Faced While Simultaneously Implementing CMMI and Scrum, Ninth International Conference on Information Technology- New Generations, p.314-318, 2012.

[10] Zhang Lina and Shao Dan, Research on Combining Scrum with CMMI in Small and Medium Organizations, International Conference on Computer Science and Electronics Engineering, p.554-557, 2012.

[11] Garzás, J., Paulk, M.C., Can Scrum help to improve the project management process? A study of the relationships between Scrum and Project Management process areas of CMMI-DEV1.3. 2013.

[12] Marcal, A.S.C., Soares, F., and Belchior, A.D., Mapping CMMI Project Management Process Areas to Scrum Practices, Proceedings of the $31^{\text {st }}$ IEEE Software Engineering Workshop, p. 13-22, 2007.
[13] Potter, N., and Sakry, M., Implementing Scrum (Agile) and CMMI Together, Scrum Alliance, 2011.

[14] Lant, M., Five Simple Steps to Agile Risk Management, Software Development, Agile Methods and the Intersection of People Process and Technology, 2010.

[15] Veethil, S.T., Risk Management in Agile, Scrum Alliance, 2013.

Eman Alharbi, born in 1986, received the Bachelor degree from Um-Alqura University department of computer science in 2009. Master student in Department of Information Technology, King Abdulaziz University, Kingdom of Saudi Arabia.

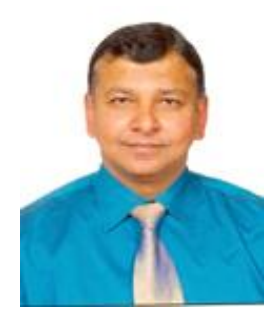

Dr. M. Rizwan Jameel Qureshi received his Ph.D. Computer Sciences degree from National College of Business Administration \& Economics, Pakistan 2009. This author is best researcher awardees from Department of Information Technology, King Abdulaziz University Saudi Arabia in 2013 and Department of Computer Science, COMSATS Institute of Information Technology Pakistan in 2008.

How to cite this paper: Eman Talal Alharbi, M. Rizwan Jameel Qureshi,"Implementation of Risk Management with SCRUM to Achieve CMMI Requirements", IJCNIS, vol.6, no.11, pp.20-25, 2014. DOI: 10.5815/ijcnis.2014.11.03 